\title{
Health Perceptions and Levels of Attachment: Owners and Pets Exercising Together
}

\author{
Mark B. Stephens, MD, MS, Cindy C. Wilson, PhD, CHES, \\ Jeffrey L. Goodie, PhD, ABPP, F. Ellen Netting, PhD, Cara H. Olsen, DrPH, \\ and Christopher G. Byers, DVM, DACVECC, DACVIM(SAIM)
}

Background: Obesity is a parallel problem in canine and human populations. We describe health perceptions and levels of companion animal attachment in a cohort of dog owners.

Methods: As part of a larger trial examining the impact of veterinary counseling on activity levels of dog owners and their pets, owners presenting to a veterinary referral center were asked to self-report perceived levels of health and attachment to their dog (Lexington Attachment to Pets Scale). Owner body mass index and the body conditioning score of the companion dog were also recorded.

Results: Heavier pet owners reported a greater sense of attachment to their dogs. Heavier owners also reported lower perceived health and less social support.

Conclusions: Increasing body mass index is associated with higher pet attachment, lower perceived health, and less social support. This information can impact wellness counseling for overweight pet owners and canine companions. (J Am Board Fam Med 2012;25:923-926.)

Keywords: Human-Animal Interaction, Obesity, Physical Activity

There is a "parallel problem" of rising overweight and obesity in both dogs and dog owners in American society. Two of every 3 American adults are either overweight or obese. ${ }^{1}$ Current estimates indicate that $25 \%$ to $40 \%$ of dogs are overweight or obese. ${ }^{2}$ Given this public health challenge, our investigation pursued a unique opportunity to examine physical activity in both pet owners and their companion animals using the family dog as a po-

This article was externally peer reviewed.

Submitted 27 November 2011; revised 16 March 2012; accepted 19 March 2012.

From the Department of Family Medicine (MBS, CCW, JLG) and Preventive Medicine and Biostatistics (CHO), Uniformed Services University, Bethesda, MD; the School of Social Work, Virginia Commonwealth University, Richmond, VA (FEN); and MidWest Veterinary Specialty Hospital, Omaha, NE (CGB).

Funding: Grant support for this project was provided by the WALTHAM ${ }^{\circledR}$ Center for Pet Nutrition.

Presented at the International Society for Anthrozoology Annual Conference, August 7, 2011, Indianapolis, IN.

Conflict of interest: none declared.

Disclaimer: The opinions herein are those of the authors. They do not represent official policy of the Department of Defense, the Department of the Navy, the US Public Health Service, or the Uniformed Services University.

Corresponding author: Mark B. Stephens, MD, MS, Uniformed Services University, USU-FAP, 4301 Jones Bridge Road, Bethesda, MD 20814 (E-mail: mstephens@usuhs.mil). tential physical activity intervention for the owner. Currently, it is not known to what degree an individual's attachment to their pet is correlated with physical activity patterns or body weight. The Owners and Pets Exercising Together (OPET) study specifically investigates human-animal interaction as a means to promote weight loss through increased levels of physical activity for both owner and animal. In this report, we describe baseline characteristics of dog owners' physical health and their levels of pet attachment.

\section{Methods}

The purpose of phase 1 of the OPET trial was to examine relationships between health characteristics and behaviors among dog owners (DOs) and their companion dogs. The Uniformed Services University's Institutional Review Board (with Institutional Animal Care and Use Committee concurrence) approved the study. Eligible participants were recruited from a specialty veterinary clinic. All dog owners $\geq 18$ years who could engage in regular physical activity and who owned a dog that was at least 2 years old and without significant cardiac or pulmonary disease, joint instability, unhealed frac- 
ture(s), and/or osteoarthritis were invited to participate. Interested individuals were given information about the study and a formal veterinary appointment was scheduled for their companion dog.

At an initial veterinary appointment, DOs completed informed consent documentation, a demographic information sheet, and self-report measures related to their perceived health, levels of physical activity, stress, social support, and level of attachment with their dog. Demographic information included DO age, sex, marital status, ethnicity, education level, occupation, and the dog's birth year. DO height and weight were assessed using a standard scale. The companion dog was also weighed and a body condition score ${ }^{3}$ determined.

DO perceived physical and mental health were measured using the physical component summary and mental component summary scores of the SF12, a validated self-report measure, using Likert responses of health-related quality of life. ${ }^{4}$ Perceived social support was reported using the Medical Outcomes Survey, which uses Likert scale responses to obtain self-reports of tangible social support, affectionate support, positive social interaction, and emotional/informational support. ${ }^{5}$ Pet attachment was assessed using the previously validated Lexington Attachment to Pets Scale. ${ }^{6}$ Activity (measured in metabolic equivalent scores) was assessed using the International Physical Activity Questionnaire. ${ }^{7}$ All data were entered into SPSS Version 18 (SPSS, Chicago, IL) for statistical analysis. Basic descriptive statistics were used for demographic analysis. Due to the ordinal nature of several of the self-report and demographic variables, the Spearman $\rho$ statistic was used for correlational analyses.

\section{Results}

Seventy-five DOs and their dogs completed Phase 1 of the OPET trial. The mean participant age was 43.5 years of age. Most participants were female, white and college-educated. The average participant body mass index (BMI; $\mathrm{kg} / \mathrm{m}^{2}$ ) was $28.5 \mathrm{~kg} / \mathrm{m}^{2}$ (Table 1). As shown in Table 2, owners with higher BMIs reported less social support $(r=-0.27 ; P=$ $.02)$ and lower perceived physical health $(r=$ $-0.20 ; P=.10$; Table 2). Owners with higher BMI also reported more attachment to their $\operatorname{dogs}(r=$ $0.29 ; P=.03)$. There was no correlation between
Table 1. Owners and Pets Exercising Together Phase 1 Demographic Data $(\mathrm{N}=75)$

\begin{tabular}{|c|c|c|}
\hline Variable & $\begin{array}{l}\mathrm{N} \text { or Mean } \\
\quad(\mathrm{SD})\end{array}$ & $\begin{array}{l}\text { Percent or } \\
\text { Range }\end{array}$ \\
\hline \multicolumn{3}{|l|}{ Sex } \\
\hline Male & 13 & 17 \\
\hline Female & 62 & 83 \\
\hline \multicolumn{3}{|l|}{ Marital status } \\
\hline Married & 36 & 48 \\
\hline Divorced & 9 & 12 \\
\hline Separated & 1 & 1 \\
\hline Never married & 29 & 39 \\
\hline \multicolumn{3}{|l|}{ Living status } \\
\hline Live alone & 15 & 20 \\
\hline Live with other(s) & 60 & 80 \\
\hline \multicolumn{3}{|l|}{ Race } \\
\hline $\begin{array}{l}\text { American Indian/Alaska } \\
\text { Native }\end{array}$ & 1 & 1 \\
\hline Black/African American & 6 & 8 \\
\hline White & 61 & 82 \\
\hline Other & 7 & 8 \\
\hline \multicolumn{3}{|l|}{ Income } \\
\hline$<\$ 20,000$ & 2 & 3 \\
\hline$\$ 20,000-\$ 40,000$ & 14 & 19 \\
\hline$\$ 40,000-\$ 60,000$ & 4 & 5 \\
\hline$\$ 60,000-\$ 80,000$ & 15 & 20 \\
\hline$\$ 80,000-\$ 100,000$ & 8 & 11 \\
\hline$>\$ 100,000$ & 32 & 43 \\
\hline \multicolumn{3}{|l|}{ Education } \\
\hline High school or GED & 4 & 5 \\
\hline Some technical school & 2 & 3 \\
\hline Technical school graduate & 3 & 4 \\
\hline Some college & 15 & 20 \\
\hline College graduate & 23 & 31 \\
\hline $\begin{array}{l}\text { Postgraduate/professional } \\
\text { degree }\end{array}$ & 28 & 37 \\
\hline \multicolumn{3}{|l|}{ Physical assessment } \\
\hline Owner age & $43.5(4.6)$ & $18-73$ \\
\hline Owner BMI* & $28.5(6.8)$ & $17.8-51.6$ \\
\hline Dog BCS & $6(1.2)$ & $4-9$ \\
\hline \multicolumn{3}{|l|}{ Self-report measures } \\
\hline LAPS & $56.5(8.6)$ & $31-68$ \\
\hline SF-12-PCS & $51.1(8.1)$ & $22-62$ \\
\hline SF-12-MCS & $50.6(9.2)$ & $18-62$ \\
\hline MOS & $4.3(0.6)$ & $2.8-5$ \\
\hline $\begin{array}{l}\text { IPAQ total METS } \\
\text { (self-reported activity) }\end{array}$ & $3493(3643)$ & $0-17,832$ \\
\hline
\end{tabular}

${ }^{*}$ BMI was available for 72 owners.

BMI, body mass index; BCS, body condition score; LAPS, Lexington Attachment to Pets Scale; PCS, physical component score; MCS, mental component summary; MOS, Medical Outcomes Survey; IPAQ, International Physical Activity Questionnaire; METS, metabolic equivalents. 
Table 2. Correlations between Body Mass Index and Self-Reported Measures of Health, Social Support, and Physical Activity

\begin{tabular}{ll}
\hline Variable & $\begin{array}{c}\text { Correlation* with } \\
\text { Owner BMI }(P)\end{array}$ \\
\hline Somatic measures & \\
Owner age & $r=0.02(\mathrm{NS})$ \\
Dog body conditioning score & $r=-0.81$ (NS) \\
Self-report measures & \\
Lexington Attachment to Pet Scale & $r=0.29(P=.03)$ \\
$\begin{array}{l}\text { SF-12 physical component scores } \\
\text { SF-12 mental component scores }\end{array}$ & $r=-0.20(\mathrm{NS})$ \\
Medical Outcome Survey social & $r=-0.02(\mathrm{NS})$ \\
$\quad \begin{array}{l}\text { support score } \\
\text { International Physical Activity } \\
\text { Questionnaire (self-reported } \\
\text { physical activity levels) }\end{array}$ & $r=-0.27(P=.02)$ \\
\hline
\end{tabular}

*Spearman $\rho$

${ }^{\dagger}$ International Physical Activity Questionnaire correlated with SF-12 physical component score $(r=0.26 ; P=.03)$.

BMI, body mass index; NS, nonsignificant.

DO BMI and self-reported measures of physical activity. There was no correlation between DO BMI and the physical conditioning score of the companion animal. An owner's perceived physical health was, however, positively associated with self-reported physical activity levels $(r=0.26 ; P=.03)$.

\section{Discussion}

Approximately $40 \%$ of US households have pet dogs and consider their animal to be part of the family. ${ }^{8}$ Dog ownership confers significant health benefits for their owners. DOs report fewer minor health issues and engage in more recreational walks than nonowners. ${ }^{9}$ Dog walking also adds to human health benefits through vicarious social support. ${ }^{10,12}$ The OPET study adds to existing literature describing the relationship between DO and their companion dogs.

First, our data suggest that overweight DOs have a less robust network of human social support and are more likely to perceive their physical health as poor. Second, overweight DOs appear to be more attached to their dogs. In this context, pet dogs likely serve as a surrogate support network for their owners. Finally, unlike previous studies, we found no correlation between owner BMI and pet body condition score. ${ }^{11}$ This last finding might relate to one of the most significant limitations of the study, the fact that all participants were re- cruited from a veterinary referral population. Individuals able to afford specialty care may innately have a higher level of pet attachment. Most participants were middle-aged, college-educated white women, further limiting the demographic and socioeconomic generalizability of our findings.

Overall, our findings have potential implications for both medical and veterinary health providers. Understanding perceived health characteristics of all patients (pets or human) as well as the relative importance of pets in an individual's life helps providers provide more specific, patient-centered counseling to promote health and wellness. We found dog owners with increased BMI are more attached to their pets, report lower perceived health, and have less social support. This information is of potential use for family physicians involved in weight management programs. When working with overweight individuals who have dogs, understanding that (at least for well-educated, affluent women) there is a high degree of pet attachment and lower general social support, physicians might be able to leverage the human-animal bond to increase physical activity. This would be of benefit for overweight owners and their pet dogs alike.

\section{References}

1. Flegal KM, Carroll MD, Ogden CL, Curtin LR. Prevalence and trends in obesity among US adults 1999-2008. JAMA 2010;303:235-41.

2. McGreevy PD, Thomson PC, Pride C, Fawcett A, Grassi T, Jones B. Prevalence of obesity in dogs examined by Australian veterinary practices and the risk factors involved. Vet Rec 2005;156:695702 .

3. Laflamme D. Development and validation of a body condition score system for dogs. Canine Pract 1997; $22: 10-5$.

4. Ware JE, Kosingki M, Keller SD. A 12-item shortform health survey: construction of scales and preliminary test of reliability and validity. Med Care 1996;4:220-6.

5. Sherbourne CD, Stewart AL. The MOS social support survey. Soc Sci Med 1991;32:705-14.

6. Johnson TP, Garrity TF, Stallones L. Psychometric evaluation of the Lexington Attachment to Pets Scale. Anthrozoos 1992;5:160-75.

7. Hallal, PC, Victora CG. Reliability and validity of the International Physical Activity Questionnaire (IPAQ). Med Sci Sports Exerc 2004;36:556.

8. American Veterinary Medical Association. US pet ownership \& demographics sourcebook. Schaumberg (IL): AMVA; 2007. 
9. Yabroff KR, Troiano RP. Walking the dog: is pet ownership associated with physical activity in California? J Phys Act Health 2008;5:216-28.

10. Wood L, Giles-Corti B, Bulsara M. The pet connection: pets as a conduit for social capital? Soc Sci Med 2005;61:1159-73.
11 Nijland ML, Stam F, Seidell JC. Overweight in dogs, but not in cats is related to overweight in their owners. Public Health Nutr 2010;13:102-6.

12. Bryant BK. The neighborhood walk: Sources of support in middle childhood. Monographs of the Society for Research in Child Development 1985;50. 